\title{
LUMINESCENCE OF SPELEOTHEMS: A COMPARISON OF SOURCES AND ENVIRONMENTS
}

\author{
Edward S. Brennan and William B. White* \\ Department of Geosciences, Deike Bldg., The Pennsylvania State University, University Park, PA 16802
}

\begin{abstract}
Calcite speleothems are typically coarsely crystalline, colored various shades from brown through orange and white, and strongly luminescent. For most speleothems, the color is due to higher molecular weight humic substances incorporated in the calcite crystal structure, while the luminescence is mainly due to lower molecular weight fulvic acids. The fine scale banding of luminescence intensity has importance as a climatic indicator. A suite of eighteen speleothems spanning a range of geologic and climatic settings and a range of colors from deep brown to nearly white were selected for detailed characterization and spectroscopic measurements. Spectra were measured on solid samples and on solutions prepared by dissolving the speleothems in dilute $\mathrm{HCl}$. The luminescent emission appears as a single broad band with peak wavelength varying from 390 to $450 \mathrm{~nm}$. The excitation spectra are typically more complicated, with several maxima, and show more locality-to-locality variation. The emission bands shift to longer wavelengths as the excitation bands move to longer wavelengths, indicating that a mixture of molecular species is being selectively excited. The spectra of the solutions are similar but not identical to the spectra of the crystalline solids. The decay time of the luminescence (phosphorescence) is in the range of 0.5 to 0.7 second. Comparison of speleothem spectra from caves in different climatic settings and of speleothem spectra from the same cave indicate that each speleothem produces spectra characteristic of specific overlying soils and pathways through the epikarst and the vadose zone. No features were discovered that characterize regional scale geologic or climatic settings.
\end{abstract}

\section{INTRODUCTION}

Speleothems, especially stalagmites and flowstone, have become important paleoclimate archives that provide information about continental interiors (Fairchild and Baker, 2012). Along with the isotope and trace element profiles that compose the paleoclimate signal are the color and luminescence profiles along the growth directions of the speleothems.

Numerous investigations of the color and luminescence spectra of speleothems tie the color (White, 1981) and luminescence firmly to humic substances or their calcium salts, with the most intense luminescence arising from the low molecular weight fulvic acid fraction (White and Brennan, 1989; van Beynen et al., 2001). The humic substances originate from overlying soils and are flushed into the cave on a seasonal cycle (Toth, 1998; van Beynen et al, 2000; van Beynan et al., 2002; Tatár et al., 2004; Ban et al., 2008). Details of soil characteristics, flow path through the epikarst, and precipitation intensity and distribution all influence the pattern of color and luminescence banding for any particular speleothem.

The objective of the present investigation is to compare the luminescence spectra of speleothems collected from a variety of climatic settings. As such, this paper extends the excellent investigation of speleothem luminescence by van Beynan and his colleagues (van Beynan et al., 2001).

\section{Experimental Methods}

\section{Sources of Speleothems}

The speleothems examined are listed in Table 1 arranged by sample number. The sample numbers refer to a master cave mineral collection built up over many years. The locations from which the speleothems were collected are given, along with a short description and a semiquantitative measure of the color determined by comparison with the Munsell charts. All specimens discussed in this paper consist entirely of calcite. Aragonite- and gypsum-containing speleothems were excluded.

\section{Luminescence Spectroscopy}

UV-excited luminescence measurements were made on a Hitachi F-4010 spectrofluorophotometer. This instrument uses a xenon arc lamp as a UV source and has two 0.2-m grating monochromators allowing both excitation and emission scanning. For a few spectra, a filter with a sharp cut-off at $400 \mathrm{~nm}$ was placed over the emission spectrometer entrance slits to eliminate artifacts from higher orders of the diffraction grating. The instrument can accommodate both liquid and solid samples and so could be used to compare the spectra of solutions with the spectra of the original solid speleothem.

\footnotetext{
* Corresponding author: wbw2@psu.edu
} 
Table 1. Description and sources of speleothems examined.

\begin{tabular}{cll}
\hline Number $^{\text {a }}$ & \multicolumn{1}{c}{ Color and Form ${ }^{\mathrm{b}}$} & \multicolumn{1}{c}{ Cave Source } \\
\hline 12 & Stalagmite & Weller's Cave, Pa. \\
61 & Orange-pink crystal [7.5YR 8/4] & Tintic Mine Cave, Utah \\
155 & Dark brown stalactite [5YR 2.5/1] & Lawrence Dome Pit Cave, W.Va. \\
166 & Colorless clear crystal & Crystal Ball Cave, Ariz. \\
305 & Gray stalagmite [10Y 7/1] & Butler Cave, Va. \\
669 & Tan stalactite [10YR 8/2] & Overholt Blowing Cave, W.Va. \\
675 & Tan stalactite [2.5Y 8/4] & Hesston Cave, Pa. \\
690 & Yellow-brown stalactite [2.5Y 8/5] & Prah Cave, Pa. \\
691 & Orange-brown stalactite [7.5YR 5/6] & Prah Cave, Pa. \\
706 & Yellow-orange stalactite [2.5Y 8/6] & Cueva del Guacharo, Venezuela \\
743 & Colorless clear crystal & Crystal Ball Cave, Ariz. \\
841 & White flowstone & Timpanogos Cave, Utah \\
844 & White stalactite & Timpanogos Cave, Utah \\
1013 & White monocrystalline stalactite & Cueva del Guacharo, Venezuela \\
1014 & Orange-brown stalactite [7.5YR 5/8] & Cueva del Guacharo, Venezuela \\
1067 & Tan stalactite [2.5Y 8/4] & Coffee River Cave, Jamaica \\
$82 \mathrm{MM004}$ & Dark brown stalactite [5YR 3/2] & Peacock Cave, W.Va. \\
$83 \mathrm{MM005}$ & Dark brown crevice filling [5YR 3/2] & Rilda Canyon, Utah \\
\hline
\end{tabular}

${ }^{a}$ Sample numbers refer to a collection of cave materials maintained by the corresponding author.

${ }^{\mathrm{b}}$ Colors are also indicated by the Munsell system (in brackets).

\section{SAmple Preparation}

Calcite is an excellent phosphor host and, under the proper excitation, can produce luminescence from incorporated transition metal ions such as $\mathrm{Mn}^{2+}$ or from charges trapped in defects in the calcite structure (White, 1990), in addition to luminescence from included organic material. By dissolving the calcite crystals, luminescent features due to transition metal ions in the crystal field of the calcite structure or to defect centers in the crystal should be eliminated. Organic molecules, however, should survive in solution. Because the electronic transitions in aromatic molecules such as humic and fulvic acids take place between molecular orbital states that are strongly localized, these molecules should retain their luminescent properties in solution. However, possible changes in the details of the spectra must be investigated.

Spectra measured on solid chips of speleothem or on dissolved fragments integrate over the luminescent banding, so the spectra of the solutions will represent a superposition of whatever distribution of molecular species that might have been present within the bands of the original speleothem. However, the spectra of individual bands, measured using laser excitation, (Crowell and White, 2012) are very similar, suggesting that the banding is more a question of concentration and humic-to-fulvic ratio rather than speciation of the fulvic component.

Bulk solutions were prepared by dissolving $425 \mathrm{mg}$ of powdered speleothem in $3.5 \mathrm{~mL}$ of $2 \mathrm{~N} \mathrm{HCl}$. The solutions were not filtered. After the powders had dissolved, any undissolved material was allowed to settle and samples of the clear liquids, which had $\mathrm{pH}$ values between 6 and 8 , were drawn off with a pipette. These solutions were placed in silica-glass cuvettes for measurement in the spectrofluorophotometer.

Measurements of luminescence spectra of solid speleothems were on cleavage chips broken to a size that would fit the sample holder of the spectrofluorophotometer. Both sawed surfaces and packed powdered samples scattered so much light from the source that plasma lines from the xenon arc appeared as artifacts in the spectra. Use of cleavage chips also avoided any artifacts that might be introduced by sawing and grinding operations. Luminescence intensities were plotted as count rates, but no scale is given since the measured intensity depends sensitively on instrument slit widths and on the exact orientation of the specimen. For this reason, one cannot compare intensities from specimen to specimen.

\section{Luminescence Spectra of Speleothems}

\section{Spectra of Speleothems in Solution}

Samples of all eighteen speleothems were dissolved, and luminescence spectra of the solutions were measured. The spectrum of each solution was scanned first to identify the main emission peak. Then, with the emission monochromator set at the wavelength of the peak, the excitation spectrum was scanned. Finally, additional emission spectra were scanned with excitation wavelength set at the maxima in the excitation spectra. Figures 1 through 3 display the spectra.

With one exception (specimen 1013), the spectra have the same general appearance. The luminescence emission spectra consist of a single broad band with peak wavelengths ranging from 369 to $438 \mathrm{~nm}$. The excitation 

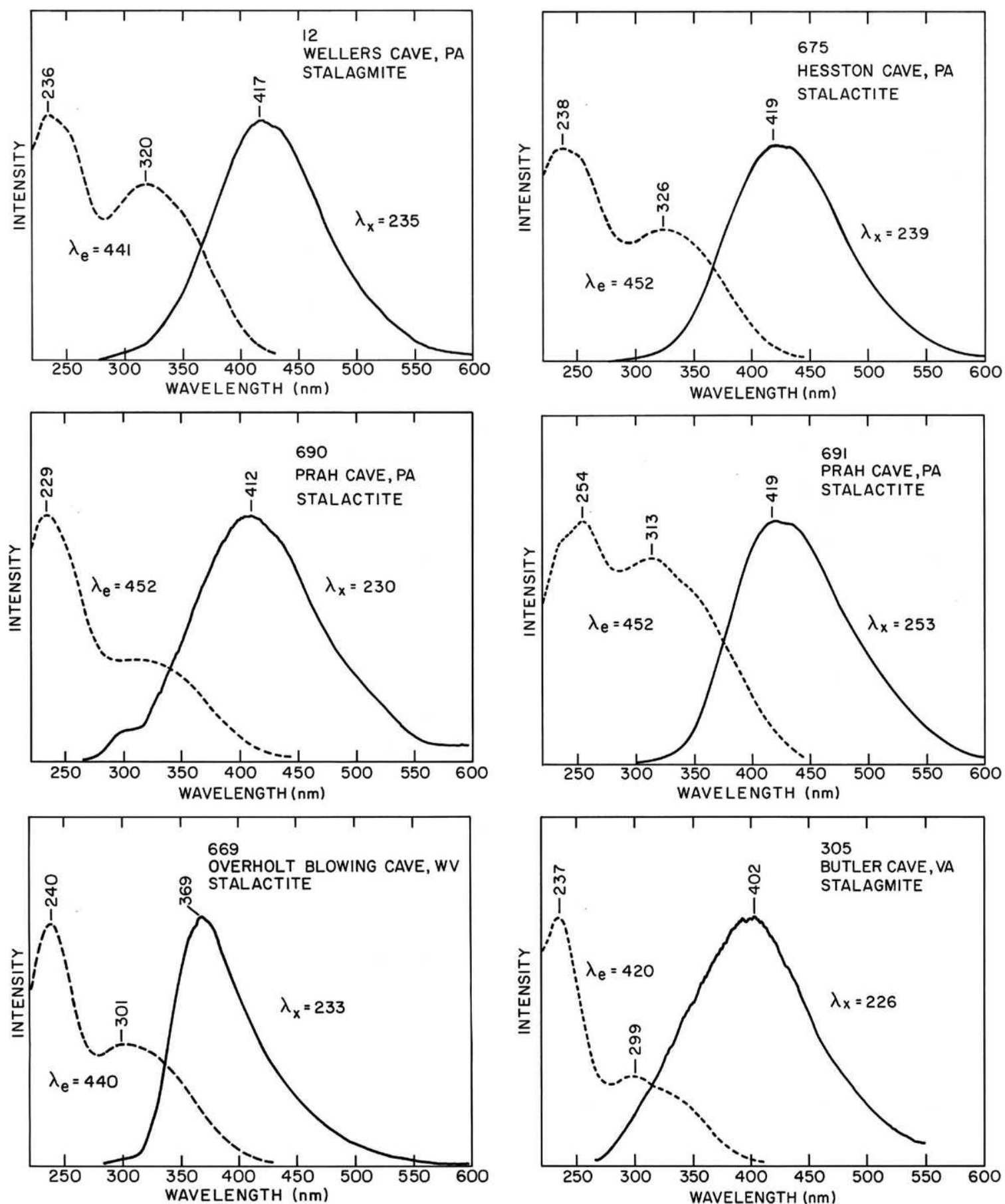

Figure 1. Emission spectra (solid lines) and excitation spectra (dashed lines) for solutions of dissolved speleothems. Excitation wavelength, $\lambda_{x}$, for emission curves and emission wavelength, $\lambda_{e}$ used to monitor excitation are labeled on the spectra. Light colored specimens taken from caves in the central Appalachians.

spectra contain at least two bands, one at short wavelengths, 230 to $250 \mathrm{~nm}$, and the other in the midultraviolet, 300 to $340 \mathrm{~nm}$. There are, however, many differences in detail from sample to sample. In some samples, the excitation bands are sharp and well separated; in others they are smeared together. The relative intensities of the two excitation bands vary widely. The emission bands shift in peak wavelength and also vary in the width of the band (full width at half maximum).

The spectra are grouped by climatic setting. Eight spectra of speleothems from the temperate climate of Pennsylvania, Virginia, and West Virginia may be compared with four spectra from tropical speleothems from Jamaica and Venezuela, and these in turn with six spectra of 

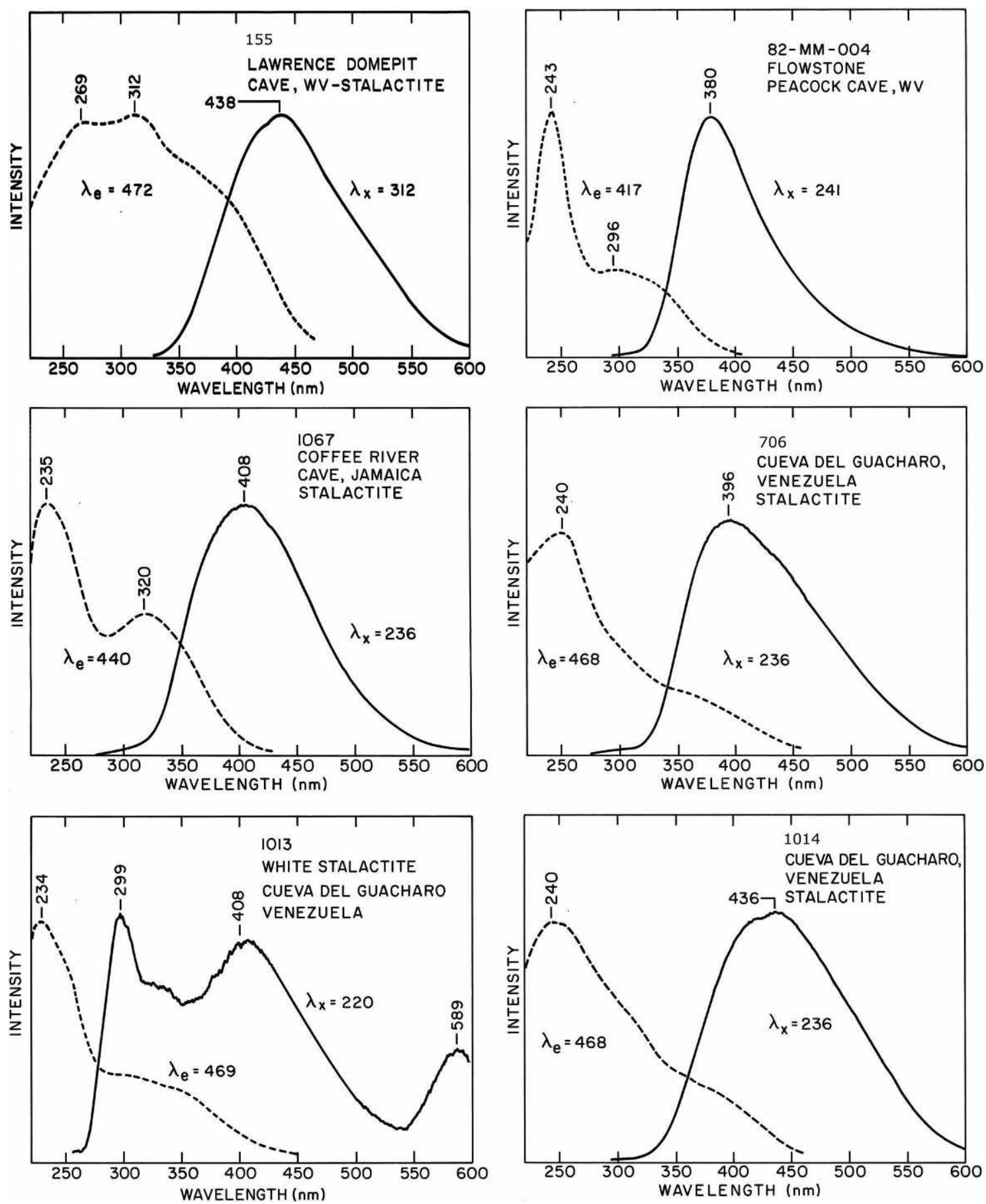

Figure 2. Emission and excitation spectra, as in Figure 1, for solutions of dissolved speleothems. Two dark-colored specimens from the Appalachians and four specimens from tropical caves.

speleothems from the semi-arid climates of Arizona and Utah. There are no systematic differences between these climatic groups.

The samples were deliberately chosen to represent a range of color (given in Munsell notation in Table 1), and therefore, presumably, the concentration of humic substances. Within the specimen set from Pennsylvania, Virginia, and West Virginia, the specimens from Overholt
Blowing Cave and from Butler Cave were very light colored, the Prah Cave specimens were a yellow-orange color, and the Peacock Cave and Lawrence Domepit Cave samples were a deep chocolate brown. In spite of the range in colors, the emission spectra are all roughly similar. There are no distinctive differences between the lightly colored and deeply colored specimens. This is in agreement with the hypothesis that the luminescence arises mainly from low molecular 

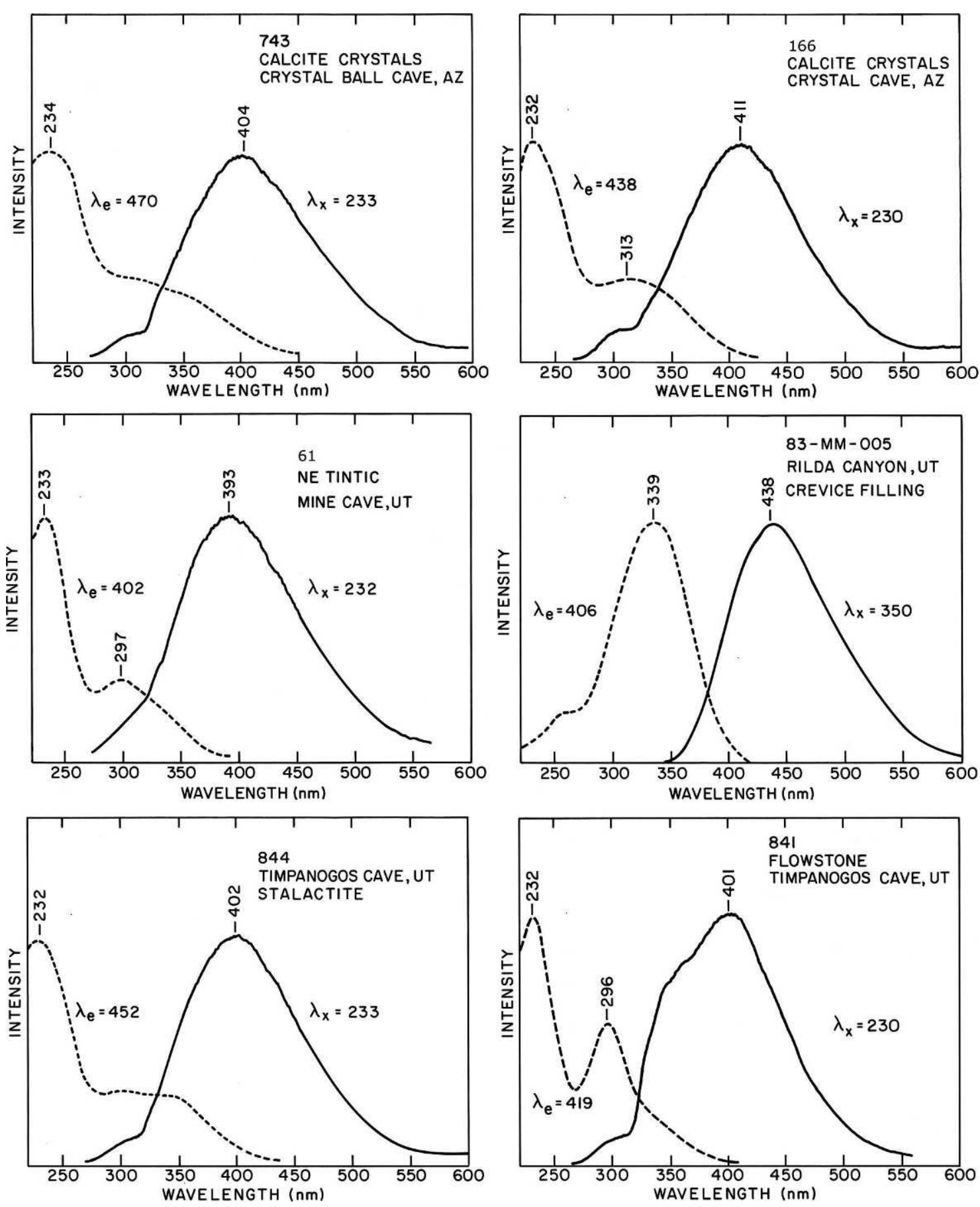

Figure 3. Emission and excitation spectra, as in Figure 1, for solutions of dissolved speleothems. Specimens taken from caves in semi-arid environments.

weight fulvic acids, while the colors arise from mainly high molecular weight humic acids. What is different over the observed range in color is the concentration of humic acids. Self-absorption within the strongly colored specimens may lower the effective intensity of the luminescence.

The Prah Cave samples (specimens 690 and 691 in Fig. 1) are instructive. These two stalactites were taken from the same cave, at a separation of only a few tens of meters, and yet the spectra are distinctly different. The comparison is even stronger with the two specimens from Timpanogos Cave (Fig. 3). Both nearly colorless specimens are from a cave at high elevation in the Wasatch Mountains. It is quite clear that each speleothem has its own individual spectral signature that was determined by local details of soil and flow path. The spectra cannot be used to label a particular climatic or geologic setting. 


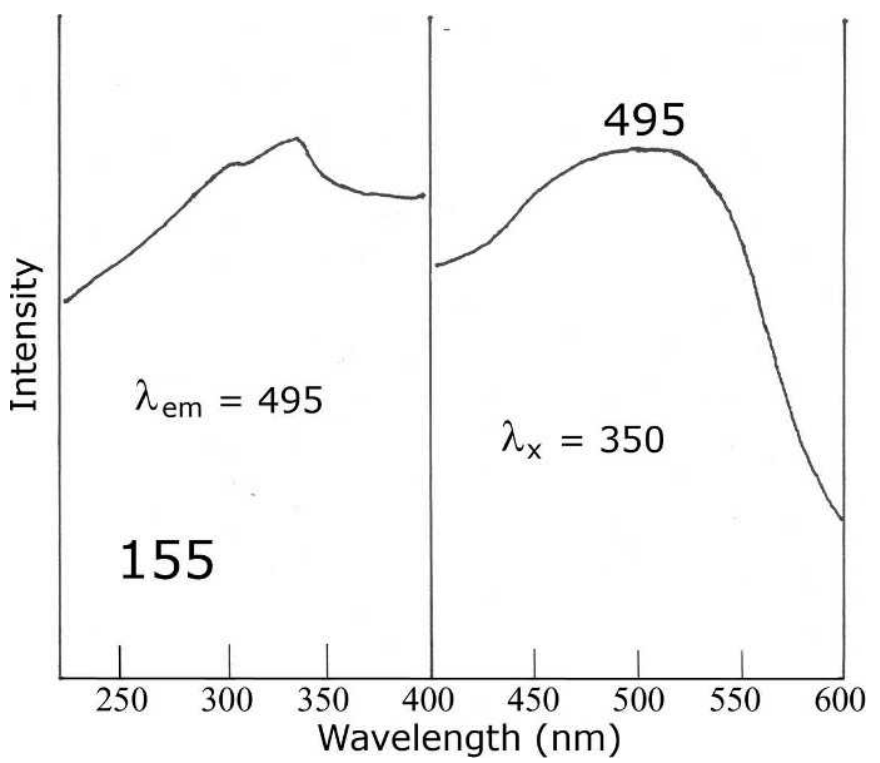

Figure 4. Emission and excitation spectra for solid chips of the chocolate-brown speleothem 155.

The three stalactites from Cueva del Guacharo in southeastern Venezuela (Fig. 2) offer the most interesting contrast. Specimen 706 was a yellow-tan, coarsely crystalline stalactite. It produces a single broad luminescence band peaking at the edge of the ultraviolet. Specimen 1013 was a pure white stalactite that had grown as a single crystal, breaking along the rhombohedral-calcite cleavage planes. The emission spectrum is complex, with an emission band at $299 \mathrm{~nm}$, a main band at $408 \mathrm{~nm}$, and a weak emission at $589 \mathrm{~nm}$. Specimen 1014 was a deep orange, almost red color. The broad main luminescence band peaks at $436 \mathrm{~nm}$, but the visible luminescence under long wave UV is a deep yellow.

Fulvic acid is a complex group of molecules based on aromatic phenolic and benzoic acid rings. The luminescence arises from triplet-to-singlet transitions within the rings, and as such, would be expected to exhibit broad, gaussian emission-line shapes. Following the usual custom for luminescent materials, the spectrometer that plotted Figures 1-3 used a wavelength scale. The gaussian shape would be more apparent on a wavenumber scale. However, the range in band widths indicates that these spectra are a superposition of the spectra of a mix of molecules within the samples.

\section{Spectra of Chrstalline Speleothems}

The deeply-colored chocolate-brown speleothems were very similar in appearance and were taken from two caves in the same climatic and vegetative environment in eastern West Virginia. Specimen 155, from Lawrence Domepit Cave, has a broad, poorly-defined excitation spectrum and also a broad emission peak that changed little with excitation wavelength. Only one example is shown in

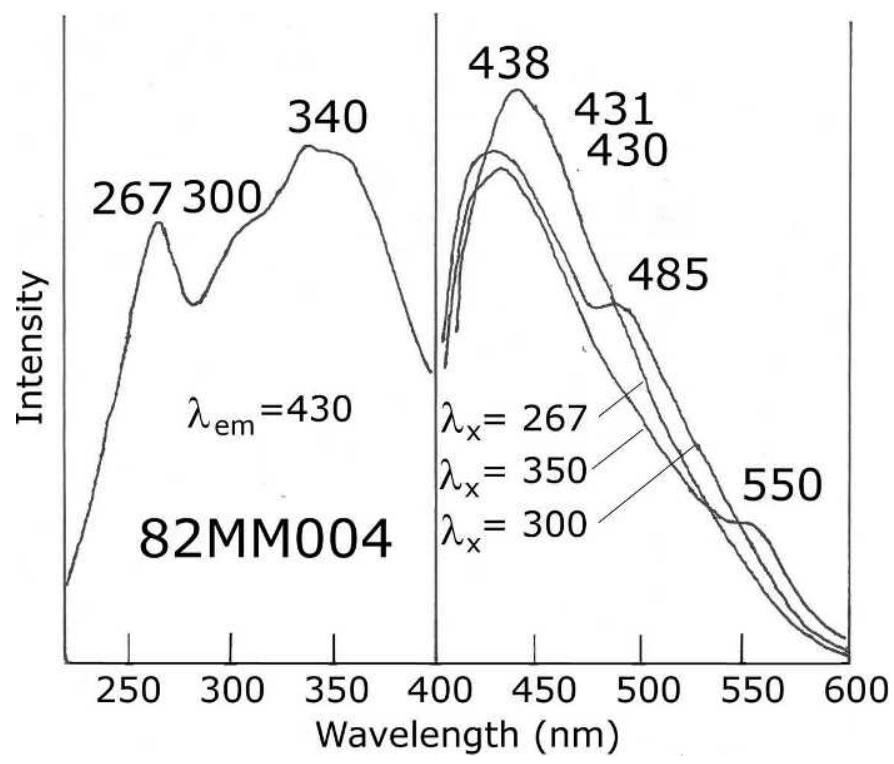

Figure 5. Emission and excitation spectra for solid chips of deep brown, coarsely crystalline speleothem 88MM004. The emission spectrum of specimen 88MM004 displays the emission at three excitation wavelengths.

Fig. 4. In contrast, specimen 82MM004, from Peacock Cave, has distinct excitation bands and excitation into each of those bands produces a different spectrum (Fig. 5).

The specimens of most interest are those from Cueva del Guacharo. These specimens were obtained from the back section of the cave, which requires a free dive though a 4-meter sump to reach. These speleothems grew at high humidity and (probably) high $\mathrm{CO}_{2}$ pressure in a section of the cave sealed off from outside air. The calcite is very coarse grained and free of any included dust or other solid matter. Indeed, specimen 1013 was a stalactite composed of a single crystal $10 \mathrm{~cm}$ in length. Photographs and a diagram of specimens 1013 and 1014 appear in a review article on speleothem growth (White, 2012).

Excitation into the broad $370-\mathrm{nm}$ excitation band of specimen 706 produces the expected broad luminescence emission at $455 \mathrm{~nm}$, but excitation at $250 \mathrm{~nm}$ produced an additional pair of sharp bands at 502 and $520 \mathrm{~nm}$, characteristic of the uranyl, $\mathrm{UO}_{2}^{2+}$ ion (Fig. 6). The visual luminescence of this specimen under short wave $(254 \mathrm{~nm})$ UV is the bright green characteristic of uranium salts (Jørgensen and Reisfeld, 1982).

The spectrum of solid chips of the white stalactite, specimen 1013 (Fig. 7), is distinctly different from the spectrum of the dissolved specimen (Fig. 2). There is the expected two-band excitation spectrum and only a single broad emission band at $405 \mathrm{~nm}$. The visual luminescence of this specimen is a weak blue-white. The deep orange-red specimen, 1014, has an almost flat excitation band and a very broad emission band at $518 \mathrm{~nm}$ that is almost independent of excitation wavelength (Fig. 8). There is a

Journal of Cave and Karst Studies, December 2013 215 


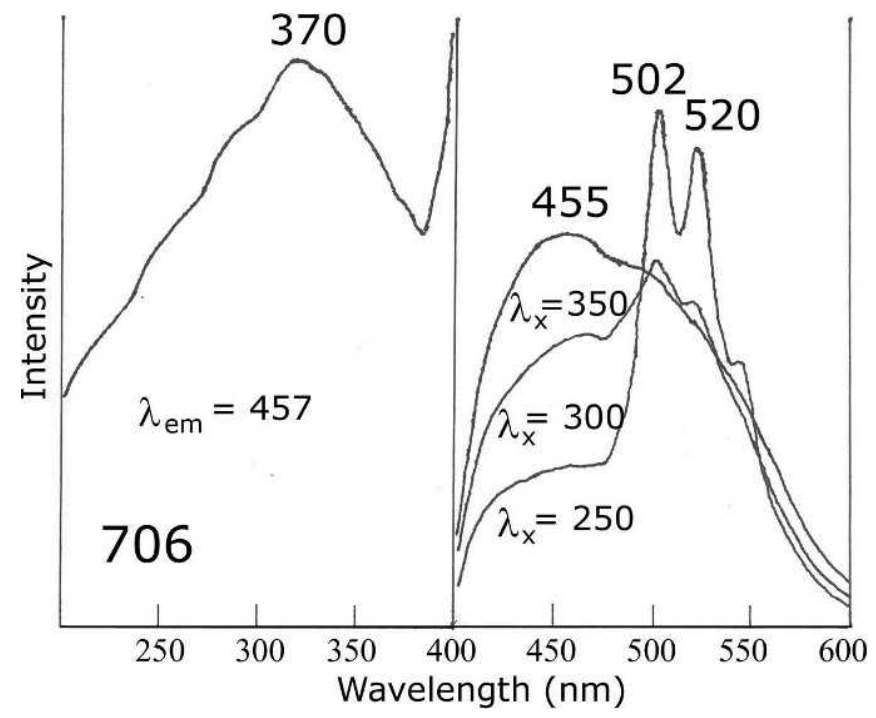

Figure 6. Emission and excitation spectra for specimen 706. The emission spectra exhibit the characteristic fulvic acid band under $350-\mathrm{nm}$ excitation, but the characteristic $\mathrm{UO}_{2}^{2+}$ bands under 250-nm excitation.

shift in peak wavelength from 518 under $375-\mathrm{nm}$ excitation to 485 at $225-\mathrm{nm}$ excitation.

\section{Luminescence Decay Time}

Quantitative measurements of the phosphorescence lifetime were made for five specimens (Fig. 9). A single decay process would be described by an exponential function of the form $I=I_{0} e^{-k t}$, where $I$ is measured

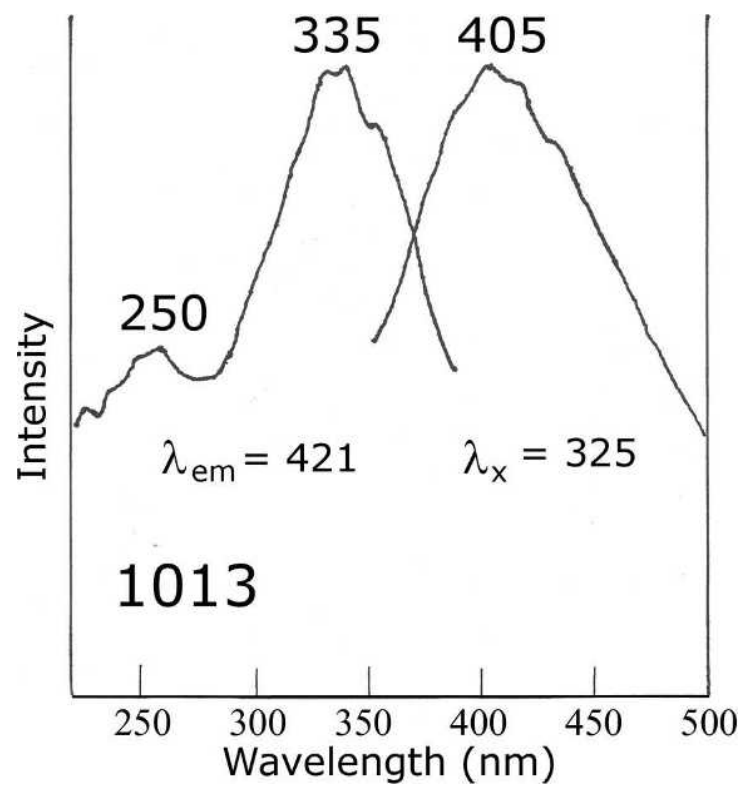

Figure 7. Emission and excitation spectra for specimen 1013, a white single-crystal stalactite.

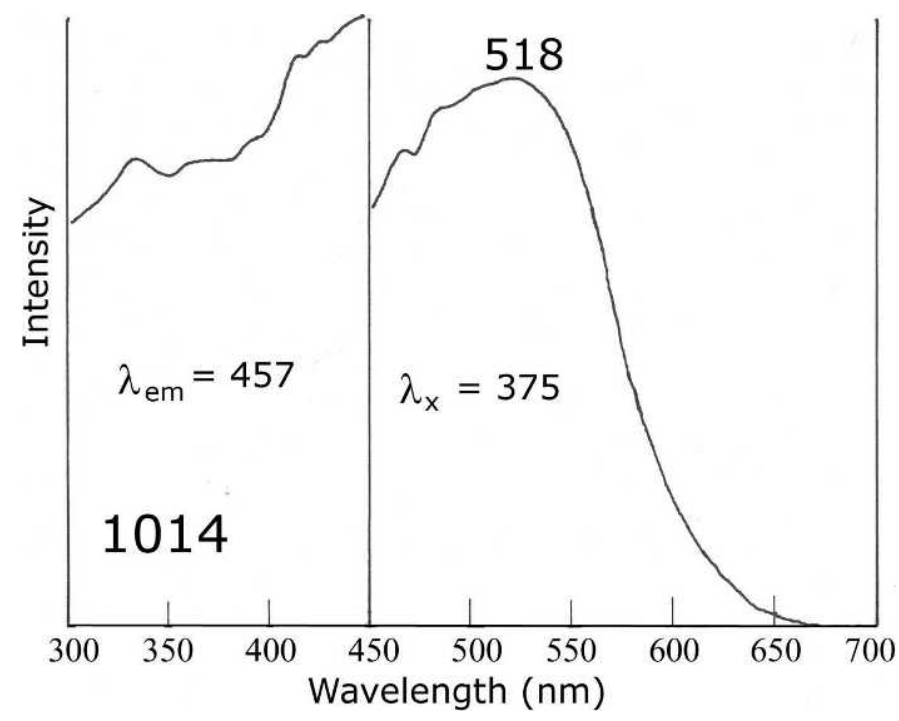

Figure 8. Emission and excitation spectra for specimen 1014, a deep orange-red stalactite. The broad emission band of specimen 1014 shifts slightly with decreasing excitation wavelength: 520 (325), 500 (300), 495 (275), 490 (250), and 485 (225).

luminescence intensity at time, $t$. The rate constant, $k$, is the reciprocal of the characteristic decay time. The measured decay characteristics vary somewhat from one specimen to another, but all decay curves have the same shape. The decay curves deviate from the single exponential, which would plot as a straight line on the semi-log plot. This implies that there is a distribution of decay rates both within any given specimen and also between specimens and is further evidence for a varying mix of fulvic acid species both within and between specimens.

Fitting the data for each specimen to a single exponential function gives an effective decay constant for that specimen. The decay constant obtained by averaging over all five specimens is $k=1.51 \mathrm{~s}^{-1}$, a decay time of $0.664 \mathrm{~s}$. These values are in the expected range for triplet $\rightarrow$ singlet transitions and are also in agreement with the visual phosphorescence of the speleothems.

\section{Discussion And Conclusions}

Luminescence banding in speleothems, as originally described, provides a useful record of growth rates and seasonal variation in precipitation. However, it is apparent from the data collected by Van Beynan et al. (2001) and in the present investigation that the detailed luminescence spectra are highly specific to not only the individual cave, but also to the specific flow path that feeds the sampled speleothem, to the type and thickness of soil overlying the cave, and to specific details of the vegetation that was growing on the surface at the time the speleothem was deposited. No evidence was found for a regional-scale 


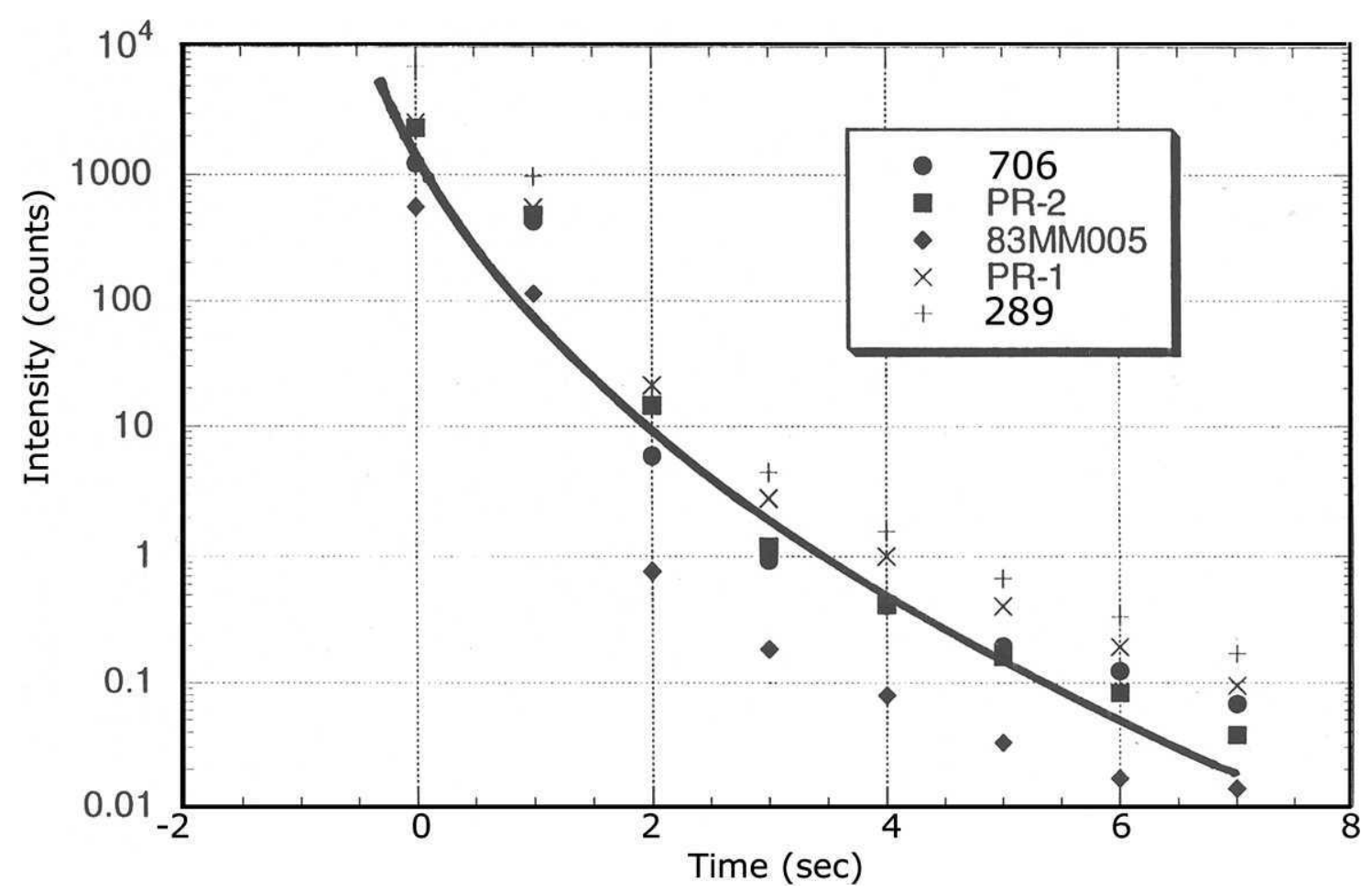

Figure 9. Luminescent decay curves for speleothems 706, PR-2, 83MM005, PR-1, and 289.

pattern that would relate to either the geologic or the climatic setting of the cave.

Luminescence spectroscopy has proved to be a useful method for the characterization of humic substances in soils (Senesi et al., 1991). The application of luminescence spectroscopy to speleothems, especially speleothems that have established ages, would be an approach to the study of changes in soil and vegetative cover over time.

\section{REFERENCES}

Ban, Fengmei, Pan, Genxing, Zhu, Jian, Cai, Binggui, and Tan, Ming, 2008, Temporal and spatial variations in the discharge and dissolved organic carbon of drip waters in Beijing Shihua Cave, China: Hydrological Processes, v. 22, p. 3749-3758. doi:10.1002/hyp.6979.

Crowell, B.E., and White, W.B., 2012, Measurement of luminescent banding in speleothems: some techniques and limitations: International Journal of Speleology, v. 41, p. 51-58. doi:10.5038/1827806X.41.1.6.

Fairchild, I.J., and Baker, A., 2012, Speleothem Science: From Process to Past Environments: Chichester, Wiley-Blackwell, 432 p.

Jørgensen, C.K., and Reisfeld, R., 1982, Uranyl photophysics, in Clark, M.J., ed., Topics in Inorganic and Physical Chemistry: London, Springer, Structure and Bonding series, v. 50, p. 121-171. doi:10. 1007/3-540-11454-8.

Senesi, N., Miano, T.M., Provenzano, M.R., and Brunetti, G., 1991, Characterization, differentiation, and classification of humic substances by fluorescence spectroscopy: Soil Science, v. 152, p. 259-271.

Shopov, Y.Y., Dermendjiev, V., and Butkliev, G., 1989, Investigation of the old variations of the climate and solar activity by a new method -
LLMZA of cave flowstone from Bulgaria: Proceedings of the 10th International Congress of Speleology, Budapest, p. 95-97.

Tatár, E., Mihucz, V.G., Zámbo, L., Gasparics, T., and Záray, G., 2004, Seasonal changes of fulvic acid, $\mathrm{Ca}$ and $\mathrm{Mg}$ concentrations of water samples collected above and in the Béke Cave of the Aggtelek karst system (Hungary): Applied Geochemistry, v. 19, p. 1727-1733. doi:10.1016/j.apgeochem.2004.03.011.

Toth, V.A., 1998, Spatial and temporal variations in the dissolved organic carbon concentrations in the vadose karst waters of Marengo Cave, Indiana: Journal of Cave and Karst Studies, v. 60, p. 167-171.

van Beynen, P., Ford, D., and Schwarcz, H., 2000, Seasonal variability in organic substances in surface and cave waters at Marengo Cave, Indiana: Hydrological Processes, v. 14, p. 1177-1197. doi:10.1002/ (SICI)1099-1085(200005)14:7<1177::AID-HYP7>3.0.CO;2-Q.

van Beynen, P., Bourbonniere, R., Ford, D., and Schwarcz, H., 2001, Causes of colour and fluorescence in speleothems: Chemical Geology, v. 175, p. 319-341. doi:10.1016/S0009-2541(00)00343-0.

van Beynen, P.E., Schwarcz, H.P., Ford, D.C., and Timmins, G.T., 2002, Organic substances in cave drip waters: studies from Marengo Cave, Indiana: Canadian Journal of the Earth Sciences, v. 39, p. 279-284. doi:10.1139/e01-072.

White, W.B., 1981, Reflectance spectra and color in speleothems: NSS Bulletin, v. 43, p. 20-26.

White, W.B., and Brennan, E.S., 1989, Luminescence of speleothems due to fulvic acid and other activators: Proceedings of the 10th International Congress of Speleology, Budapest, Hungary, p. 212-214.

White, W.B., 1990, Photoluminescence, candoluminescence, and radical recombination luminescence of minerals, in Coyne, L.M., McKeever, S.W.S., and Blake, D.F., eds., Spectroscopic Characterization of Minerals and Their Surfaces: American Chemical Society, Symposium Series, v. 415, p. 118-134. doi:10.1021/bk-1990-0415.ch006.

White, W.B., 2012, Speleothem microstructure/speleothem ontogeny: a review of Western contributions: International Journal of Speleology, v. 41, p. 329-358. doi:10.5038/1827-806X.41.2.18. 